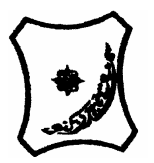

Bayero Journal of Pure and Applied Sciences, 9(2); 230 - 233

Received: April, 2016

Accepted: August, 2016

ISSN $2006-6996$

\title{
STRUCTURAL ANALYSIS AND SURFACE MORPHOLOGY OF QUARTZ
}

\author{
Hassan Usman Jamo \\ Department of Physics, Faculty of Science, Northwest University P.M.B. 3220 Kano, Nigeria. \\ 08104970536,jamouhfce@gmial.com
}

\begin{abstract}
The structural analysis and surface morphology of quartz has been studied. Quartz has long been known to be a source of silica. X-ray fluorescence (XRF), X-ray diffraction (XRD) and scanning electron microscopy (SEM) were used to observe the surface and internal structure of the quartz. The results among other things revealed that the quartz consist of mainly silica $\left(\mathrm{SiO}_{2}\right)$, with crystalline structure, microscopic examination showed that the quartz has a porous cellular structure and consists of irregular-shaped particles. This study implies that quartz is good candidate for various applications by ceramic industries.

Key words: Quartz; XRF;XRD; SEM; TGA
\end{abstract}

\section{INTRODUCTION}

Quartz is the second most abundant mineral in Earth's crust after feldspar. It occurs in nearly all acid igneous, metamorphic, and sedimentary rocks(Baskin, 1956; Bömmel and Dransfeld 1960; Clake and Washington, 1924; Davis,2007). It is an essential mineral in such silica-rich felsic rocks as granites, granodiorites, and rhyolites. It is highly resistant to weathering and tends to concentrate in sandstones and other detrital rocks. Secondary quartz serves as cement in sedimentary rocks of this kind, forming overgrowths on detrital grains. Microcrystalline varieties of silica known as chert, flint, agate, and jasper consist of a fine network of quartz. Metamorphism of quartz-bearing igneous and sedimentary rocks typically increases the amount of quartz and its grain size(Grant, 1985).

It has been called the "Universal Crystal" because of its many uses. It enhances energy by absorbing, storing, amplifying, balancing, focusing and transmitting(Hwang et al., 2006). It channels universal energy. Because it directs and amplifies energy, it is extremely beneficial for manifesting, healing, meditation, protection, and channeling. It is also beneficial for storing and retrieving information of all types, as information is a form of energy pattern also. This makes them particularly good for programming to use for a particular purpose. Due to its ability to balance, quartz is excellent for harmonizing and balancing one's environment. Quartz is also good for energizing other crystals(Iida and Kimura, 2005).

Pure quartz $\left(\mathrm{SiO}_{2}\right)$ has three common polymorphs: cristobolite, tridymite (high-temperature), and quartz (low-temperature). The silica structure is the basic structure for glasses and many ceramics. The structure of a material may be divided into four levels: atomic structure, atomic arrangement, microstructure, and macrostructure. On the atomic level, quartz has an internal arrangement consisting of pyramid (tetrahedral or four-sided) units. Four large oxygen (O) atoms surround each smaller silicon ( $\mathrm{Si}$ ) atom. The silicon atoms occupy the openings (interstitials) between the oxygen atoms and share four valence electrons with the oxygen atoms through covalent bonding (Konesni, 2010).

The silicate structures can link together by sharing the atoms in two corners of the $\mathrm{SiO}_{2}$, tetrahedrons, forming chain or ring structures. By sharing three corner atoms, they produce layered silicates (talc, kaolinite clay, mica); or by sharing four comer atoms, they produce framework silicates (quartz, tridymite). The alternating $\mathrm{Si}$ and $\mathrm{O}$ covalent bonding is most common in ceramics and compares to the carbon to carbon (C-C) bonding in organic materials (O'sullivan and Guilbaut, 1999).

Quartz crystals have piezoelectric properties, meaning that they are capable of changing a mechanical force into electricity, or an electric current into a mechanical force. A slice, or wafer, of quartz crystal will generate an electric current when it is subjected to pressure. Conversely, a wafer connected in an alternating electric circuit will expand and contract, or oscillate, at a fixed frequency. This frequency depends on the thickness of the wafer. Thin wafers oscillate at higher frequencies than thick ones (Paton, 1995).

Quartz crystal wafers are used to control the frequencies of oscillating electric circuits in quartz watches and radio transmitters. They are also used to convert electric signals into sound waves in devices such as sonar and ultrasonic generators. In such devices as hearing aids and submarine detectors, quartz crystals convert weak sound waves into electric current, which is then amplified and reconverted into sound waves. Some phonographs use quartz crystals to convert vibrations of the stylus (needle) into electric impulses. For electronic use, a quartz crystal must be flawless. Most of the crystals now used in electronics are synthetic (O'sullivan and Guilbaut, 1999; Patton, 1995). 
Rock crystal is used to make lenses and prisms for optical instruments. Quartz is also used to make glass, mortar, grindstones, sandpaper, and cleaning compounds. It is used as a flux in the smelting of iron and copper ores, and as a glaze for porcelain. Such varieties of quartz as agate, amethyst, onyx, and sardonyx are used as gems (Waltham, 2001).

However, despite these applications of quartz literature on the structural and morphology of quartz has not being reported. Hence therefore, this paper reports the results of an investigation into the structural analysis of quartz using $X$-ray fluorescence (XRF), Scanning electron micrographs (SEM) and Xray diffraction (XRD). The aim was to study the structure and surface morphology of quartz.

\section{Experimental (Methodology)}

The following tests were conducted to characterize the quartz.

\section{$\mathbf{X}$-ray Fluorescence (XRF)}

$X$-ray fluorescence (XRF) is the emission of characteristic "secondary" (or fluorescent) X-rays from a material that has been excited by bombarding with high-energy $\mathrm{X}$-rays or gamma rays. The phenomenon is widely used for elemental analysis and chemical analysis, particularly in the investigation of metals, glass, ceramics, building materials and for research in geochemistry, forensic science and archaeology.

The quartz used in this study was obtained from the local supplier (Maju Saintifik Sdn Bhd) Malaysia, which is in powder form. The powders were pressed into pellets with ratio 8:2, powder to wax. The mould pressure used in producing the pellets is 8 tonnes and hold time is one minute. The samples were placed in the XRF machine for elemental analysis. The machine (XRF Bruker S4 Pioneer) was operated at $60 \mathrm{KV}$.

\section{Scanning Electron Microscopy}

JOEL-JSM-6380 instrument was used to study the morphology of the quartz which is available at Mechanical Laboratory, UniversitiTun Hussein Onn Malaysia (UTHM). Small amount of quartz powder was poured on the carbon tape which is attached to the holder. Then the excess powder was blown with air gun to ensure that small pieces of the powder remain on the tape. After that it was put into in the SEM chamber for analysis. The SEM machine was operated at operated at $10 \mathrm{kV}$. The magnification of $\mathrm{X} 1000$ is used to capture photo of the sample.

\section{Quartz through X-Ray Diffraction (XRD)}

The quartz samples were subjected to X-Ray Diffraction (XRD) analysis using an X-Ray Diffractometer to determine their silica structure. Prior to analysis, the quartz samples were ground to a powder form by simple pounding using a mortar and pestle due to its brittle nature.

The ground samples were analyzed by $\mathrm{Cu}$ Ka radiation with a scanning rate of $0.05^{\circ}$ per second $40 \mathrm{kV}$, speed $0.05^{\circ} / \mathrm{min}$ and scanning at $3^{\circ} \geq 2 \theta \leq 90^{\circ}$. The X-Ray Diffractometer (Model Bruker D8 Advance) is available for use at the Faculty of Civil Engineering.

\section{Thermogravimetric Analysis (TGA)}

TGA of the quartz was determined by using Lenseis Thermobalance instrument, in Ceramics and Polymer laboratory UTHM. Information about the thermal properties of TGA especially the point is of great importance to this study. The TGA observation can give the temperature change of the sample to obtain suitable sintering temperature. To do the test little amount of TGA powder $(24.6 \mathrm{mg})$ was used for the heating and cooling. The speed of the test was $10^{\circ} \mathrm{C} /$ minutes and the maximum temperature $1000^{\circ} \mathrm{C}$.

\section{Results and Disscussion}

$\mathrm{X}$-Ray Fluorescence (XRF)analysis is proficient in analyzing material contents inside the raw materials, hence the amount of $\mathrm{SiO}_{2}$ can be observed. The presence of various compounds within quartz raw material can be seen in Table 2.Thistableshowsthe result of XRF analysis of quartz raw material. It is evident that $\mathrm{SiO}_{2}$ is the major composition in the entire raw materials quartz raw material with 99.40 wt\% followed by alumina with 0.22 wt\%.

Table 2: Chemical analysis of quartz

\begin{tabular}{llllllllllllllll}
\hline Sample & \multicolumn{1}{l}{ Content (\%wt) } \\
\hline Composition & $\mathrm{SiO}_{2}$ & $\mathrm{Al}_{2} \mathrm{O}_{3}$ & $\mathrm{FeO}_{3}$ & $\mathrm{CaO}$ & $\mathrm{K}_{2} \mathrm{O}$ & $\mathrm{P}_{2} \mathrm{O}_{5}$ & $\mathrm{MgO}$ & $\mathrm{SO}_{3}$ & $\mathrm{Na}_{2} \mathrm{O}$ & $\mathrm{MnO}$ & $\mathrm{TiO}_{2}$ & $\mathrm{CO}_{2}$ & $\mathrm{LOI}$ \\
\hline Quartz & 99.40 & 0.22 & - & - & - & - & - & - & - & - & - & 0.10 & 0.28
\end{tabular}




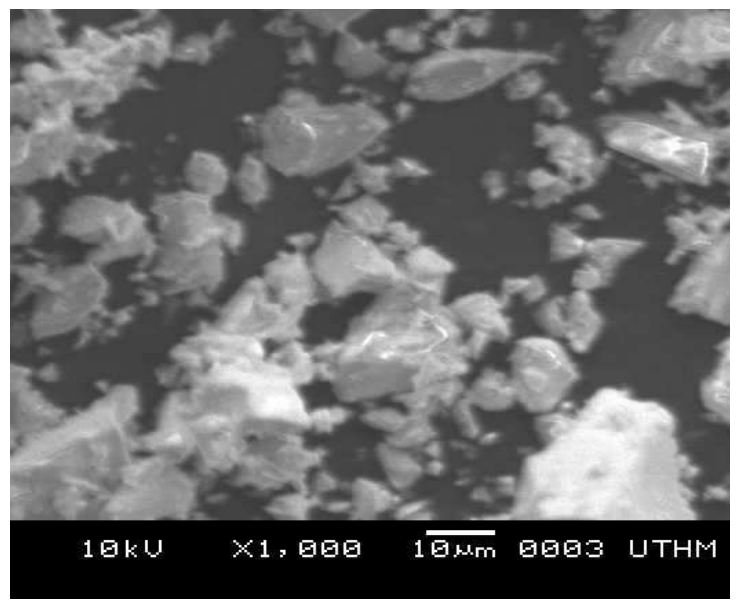

Figure 1: SEM of Quartz

Figure 1 shows the quartz particles; the particles were irregular in shape and having porous texture. In addition, there was no agglomeration of quartz particles.

Figure 2 is the qualitative XRD analysis of the quartz raw material. One major phase identified is quartz hexagonal (ICDD 0)70-3755). This result is suportive of XRF result presented in Table 1.
Quartz revealed a unique weight change profile upon heating (Figure3) with a weight lossas the temperature increases. The weight drop profile exhibited by the quartz in the temperature range of $21^{\circ} \mathrm{C}$ to $940^{\circ} \mathrm{C}$ is identical to that exhibited during the dehydration of the hydroxyl groups in kaolinite.

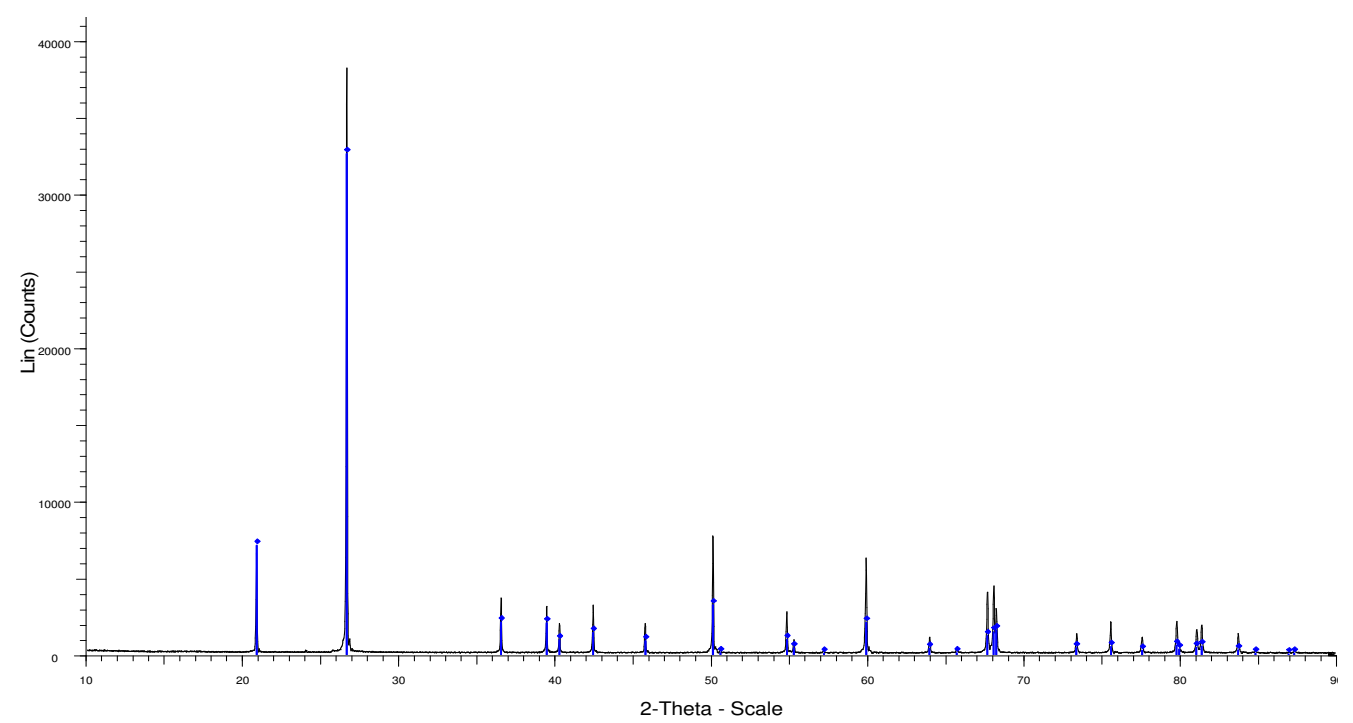

Figure 2: XRD of Quartz 


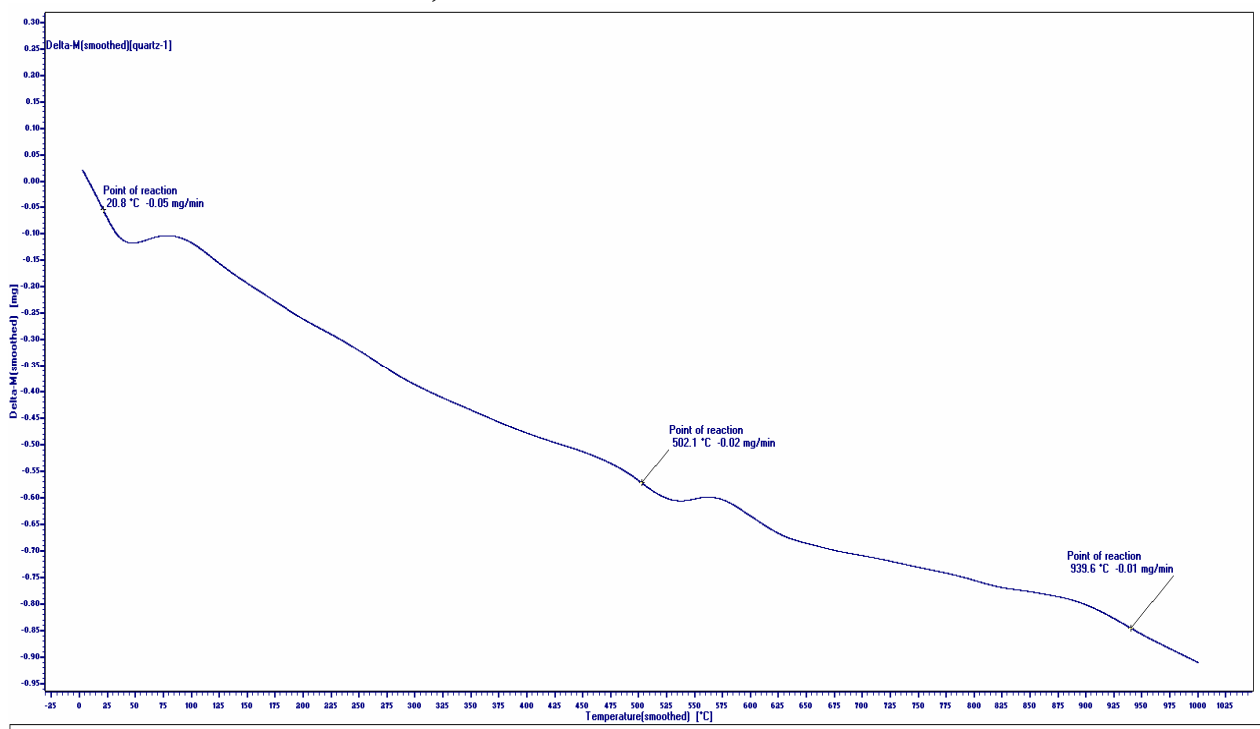

Figure 3: TGA of Quartz

\section{CONCLUSION}

Quartz isa valuablenaturalresourcenotonlyas a good source of silica, but also as asource of lignocellulosic material which can be potentially used to produce arange of valuable products. However, product development will require greater understanding of the quartz. The information provided here could form both a useful background on the compositional andmorphological characteristics of the quartz surface as well asitsinternal tissues. Therefore the extension of knowledge on structural analysis and surface morphology of this quartz is very important for the determination of which type quartz to be used by the industries.

\section{RECOMMENDATIONS}

Therefore the extension of knowledge on Differential Thermal Analysis of this quartz is very important for

\section{REFERENCES}

Baskin, Y. (1956). A study of authigenic feldspars. The Journal of Geology, 132-155.

Bömmel, H. E., \& Dransfeld, K. (1960). Excitation and attenuation of hypersonic waves in quartz. Physical Review, 11入5), 1245.

Clarke, F. W., \& Washington, H. S. (1924). The composition of the earth's crust (Vol. 127). US Government Printing Office.

Davis, C. (2007). U.S. Patent Application 11/746,675.

Grant, F. S. (1985). Aeromagnetics, geology and ore environments, I. Magnetite in igneous, sedimentary and metamorphic rocks: an overview. Geoexploration, 23(3), 303-333.

Hwang, D. J., Chimmalgi, A., \& Grigoropoulos, C. P. (2006). Ablation of thin metal films by shortpulsed lasers coupled through near-field scanning optical microscopy probes. Journal of applied physics, 99(4), 044905. the determination of which type quartz to be used by the industries.

\section{Contributions of Authors}

The Author wishes to regiter his gratitude to the following; Asso. Prof. Mohammad Zaky bin Noh and Prof. Zainal Arrifin Ahmad for their guidance duringt the conduct of this experiment.

\section{Ackwoledgement}

The authors would like to acknowledge the financial support of Universiti Tun Hussein Onn Malaysia. We would also like to thank the following Mr. Mohd Azrul Nizam bin Mustari, Mr. Fazlannuddin Hanur bin Harith, Mr. Shahrul Mahadi bin Samsudin, Mr. Mohd Tarmizi bin Nasir, Mr. Anuar bin Ismail, and Mr. Ahmad Nasrull bin Mohamed for their assistance as laboratory technicians.

Iida, M., \& Kimura, M. (2005). U.S. Patent No. $6,843,847$. Washington, DC: U.S. Patent and Trademark Office.

Konesni, M. (2010). Mandi's Metaphysical Gems. Lulu. com.

McBride, E. F. (1989). Quartz cement in sandstones: a review. Earth-Science Reviews, 26(1), 69112.

O'sullivan, C. K., \& Guilbault, G. G. (1999). Commercial quartz crystal microbalancestheory and applications. Biosensors and bioelectronics, 14(8), 663-670.

Paton, T. R. (1995). Soils: a new global view. CRC Press.

Universal Crystal" because of its many uses. It enhances energy by absorbing, storing, amplifying, balancing, focusing and transmitting.

Valeton, I. (2010). Bauxites (Vol. 1). Elsevier.

Waltham, T. (2001). Foundations of engineering geology. CRC Press. 